than paying individually for each service, while doctors don't have to chase patients for money each time they provide an uninsured service.

The precise services that are covered by an annual fee vary significantly from doctor to doctor, but often include telephone renewal of prescriptions, extra physicals for camp or school admissions, sick notes, phoned-in prescriptions and the fee for missed appointments.

Critics charge that the annual fees are a cash grab.

"In some cases, it's going far beyond the ostensible reason doctors need to charge fees and it's about a separate income," says Natalie Mehra, director of the Ontario Health Coalition.

Patients feel compelled to pay them, to ensure that they continue to have the services of a physician, Mehra adds. "Patients think: 'If I don't pay this, am I going to lose my family doctor?' Or: 'Am I going to be dropped to the bottom of the list'?"

The situation is even murkier with regard to the fees charged by private clinics, Mehra says, asserting that such facilities are using annual fees to "sell elite access to a family physician" and rack up profits. That notion is supported by recent events in Quebec, which saw the province's health insurer, Regie de l'Assurance Maladie du Quebec announce that it was investigating 11 private clinics that were billing patients anywhere from $\$ 400$ to $\$ 1500$ for uninsured services.

"It's impossible to get a [family] physician in Montreal unless you're very rich and Montreal probably has the most 'boutique clinics' in the country," Mehra says.

But doctors say that while there may be abuses in the form of physicians who charge exorbitant fees, or pressure on patients into anteing up, most are playing by the rules.

In fact, doctors charge annual fees not to make big profits, but simply to get remunerated for the work they do, says Dr. Benjamin Burko, a pediatrician in Montreal."It's well known that there are services that patients demand that are not covered by provincial medicare plans, including telephone advice and communicating and discussing lab results," says Burko.

He says the fees also make sense for patients who often require uninsured services for convenience's sake. "If you need a prescription renewed for a chronic condition and you can pay $\$ 30$ to $\$ 35$ for a physician to phone it in, or sacrifice half a day of work to get an appointment, it's almost a no-brainer," he says.

By charging a one-time fee annually "the patients get a discount and it saves administration costs for the physician," Burko explains. Fundamentally, however, the trend in annual fees speaks to the larger issue of how provincial insurers pay physicians, argues Burko. "More than 15 to $20 \%$ of a physician's work day is for services of which they get a grand total of zero." - Wendy Glauser, Toronto, Ont.

CMAJ 2011. DOI:10.1503/cmaj.109-3815

\title{
Federal budget becomes election plank
}

$\longrightarrow$ ritics and skeptics called it small and unimaginative. Opposition parties immediately indicated that they would blow it out of the Parliamentary waters and plunge Canadians into a general election. The government, though, called it "leadership."

"Our plan does not say 'yes' to every demand; it does not contain massive new spending — because that's not leadership,” Finance Minister Jim Flaherty said on Mar. 22 while unveiling the government's fiscal blueprint for 2011-12. "Leadership is about finding a balance between needs."

It should also be about vision, says Canadian Medical Association President Dr. Jeff Turnbull.

"Canadians expected to see significant changes to health care in this budget," he says. "We had hoped that we would see things like pharmacare and long-term care and national standards and accountability systems as we move towards 2014," when the current financ- ing agreement on health transfers to the provinces expires.

"Yes, there are a lot of small initiatives that impact on health, each one a good start in a direction but it has to be into a framework, an over-arching transformed health care system that serves Canadians."

Among the modest, health-related measures in the budget was a scheme to attract doctors, nurses and nurse practitioners to "under-served rural and remote" communities by forgiving a portion of their Canada Student Loans if they set up a shingle in isolated environments, commencing in fiscal 2012-13.

But exactly what constitutes such communities remains to be determined, Finance officials said, on condition of anonymity, during a background briefing on the blueprint. "Some people use population. Others use proximity to health centres. We'll have to establish a proper national standard."

Finance officials say that roughly 900 doctors and 1600 nurses graduate annu- ally in debt to the Canada Student Loans program. It's estimated the average medical student graduates with a debt load on the order of $\$ 100000$. They'll be eligible to have $\$ 8000$ per year written off their loans, to a maximum $\$ 40000$, while nurses and nurse practitioners will be eligible for a $\$ 4000$ per year write-off, to a maximum $\$ 20000$, if they undertake a stint in a remote community.

The government also allocated roughly $\$ 40$ million in 2011-12 for a non-refundable family caregiver tax credit to those providing care to infirm or dependent relatives, including spouses, common-law partners and children.

Essentially, those caring for loved ones meeting certain criteria will get a tax credit of $\$ 2000$. But as with existing health-related tax support, it will be reduced by $15 \%$ for every dollar earned (including pensions) by the person receiving care, and essentially disappear at an income level of \$21360.

In a related measure, the government eliminated the $\$ 10000$ ceiling for 
"itemizable medical and disabilityrelated expenses" (such as wheelchairs or ramps) that qualify for $15 \%$ medical expense tax credits made on behalf of a financially dependent relative. The move is projected to cost the government \$1 million in 2010-11 and \$3 million in 2011-12 and thereafter.

Other health-related measures included allowing medical students to include the fees for certification exams to be eligible for the federal tuition tax credit and setting aside $\$ 3$ million to "help support the development of new community-integrated palliative care models."

All told, the health measures are "very, very modest," says Pamela Fralick, president of the Canadian Healthcare Association, the primary voice of the nation's hospitals. "But it's an entry point and leads us to believe there will be more coming in future years."

Canadian Nurses Association President Judith Shamian called it "an election budget, a bit of something for everyone."

Others, though, were apoplectic, particularly with regard to the caregiver tax credit. "Once again, we see the Tory ideology at work, where they place the onus on the families to be the caregivers rather than investing in public health care," says Barry Thorsteinson, president of the National Pensioners and Senior Citizens Federation.

Overall, federal government spending for fiscal 2011-12 will rise by $\$ 2.7$ billion to $\$ 278.7$ billion, with Ottawa running a deficit of $\$ 29.6$ billion and the debt load rising to $\$ 586$ billion, or $34.4 \%$ of the gross domestic product.

With respect to federal transfer payments to the provinces for health, Flaherty's signal was simple and straightforward: "We will not cut transfer payments for crucial services like health care and education, unlike the previous Liberal government," (which slashed federal transfers during the mid-1990s in a bid to rein in the federal deficit). Federal transfers in support of health and social programs will rise $\$ 1.5$ billion to $\$ 38.7$ billion, while equalization payments for have-not provinces rise $\$ 500000$ to $\$ 16.9$ billion.

Modest, but deceptive, budget increases were again the order of the day for the granting councils. The Canadian

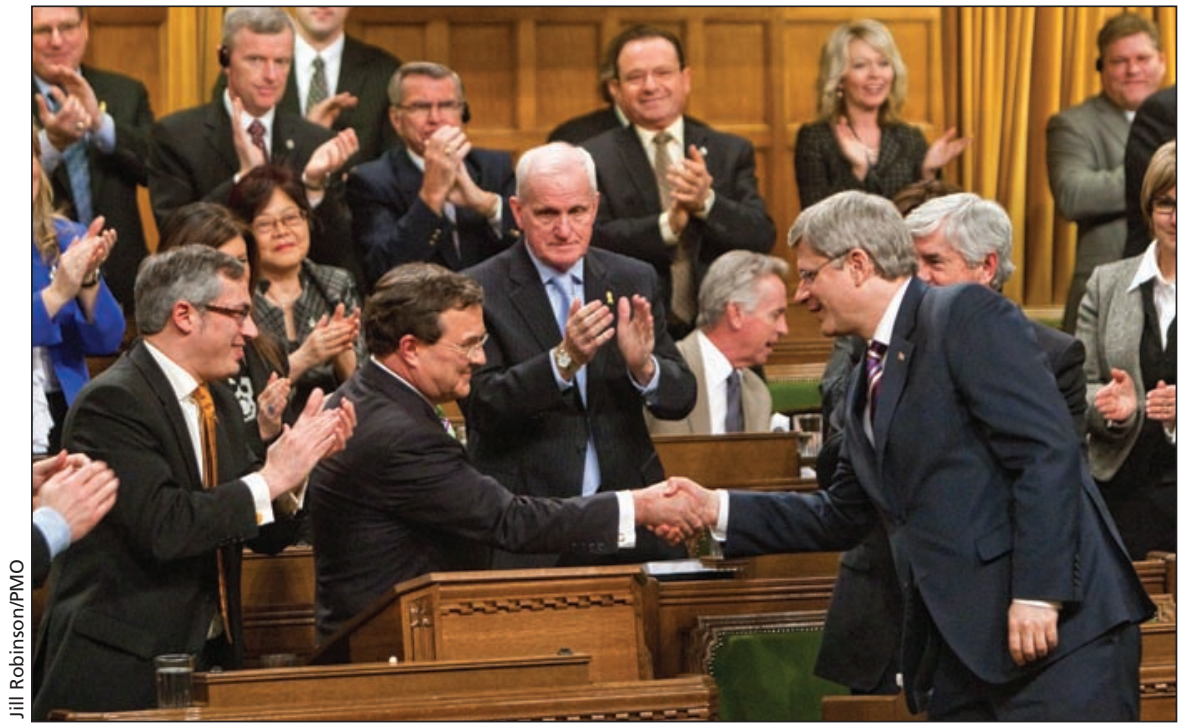

Prime Minister Stephen Harper shakes hands with Jim Flaherty after the Minister of Finance tabled the 2011-12 federal budget on Mar. 22.

Institutes of Health Research (CIHR), the Natural Sciences and Engineering Research Council (NSERC) and the Social Sciences and Humanities Research Council received a collective \$37 million - \$15 million, \$15 million and $\$ 7$ million, respectively - per year increase in their base operating budgets. But that doesn't offset the collective \$43 million hit they will take as a result of measures announced in the 2009 budget.

The government also continued its practice of supporting big-ticket science by creating 10 new Canada Excellence Research Chairs, which have provided on the order of $\$ 10$ million over seven years apiece to 19 Canadian researchers, and by again funnelling big bucks at a targeted research initiative. This year's winner was Brain Canada, a nonprofit foundation whose current honourary and former chair (2003-2006) is Michael Wilson, ex-finance minister for the Conservatives. The foundation will create a Canada Brain Research Fund, to which the government will contribute up to $\$ 100$ million to match monies raised by the organization and its partners.

Critics, including Jim Turk, executive director of Canadian Association of University Teachers, immediately assailed the move as further evidence of the government's fondness for "politically attractive," targeted initiatives that favour "star" researchers or one discipline over another.

"They have three times as much for the Canadian Brain Research Fund than they do for all the granting councils combined, Turk says, adding that it was a continuation of the pattern "where the politicians pick some research agent which may be excellent, or maybe not, and fund it rather than the granting councils."

But Inez Jabalpurwala, president of Brain Canada, says there is a substantive difference in the types of research being supported, as her foundation will fund multidisciplinary, multi-institutional, collaborative work addressing "commonalities across brain disorders."

"The difference is that CIHR primarily funds the pipeline of individuals and we fund the teams. So there is a complementarity to the way the research is funded. Without that pipeline, you can't get to the next level of excellence."

Among other health and researchrelated measures were $\$ 405$ million for Atomic Energy of Canada Ltd. to cover losses and provide "a secure supply of medical isotopes"; $\$ 4$ million toward construction of a cyclotron in Thunder Bay, Ont., to produce isotopes; $\$ 65$ million for a "human health" grants competition at Genome Canada; and \$200 million over five years for the Canadian Food Inspection Agency to improve food inspection capacity. - Wayne Kondro, CMAJ

CMAJ 2011. DOI:10.1503/cmaj.109-3845 